\title{
A Recipe for Scavenging in Vertebrates - the natural history of a behaviour
}

Adam Kane $^{1}$, Kevin Healy ${ }^{2,3}$, Thomas Guillerme ${ }^{4}$, Graeme D. Ruxton ${ }^{5}$, \& Andrew L. Jackson ${ }^{2,3}$

${ }^{1}$ University College Cork, Cooperage Building, School of Biological Earth and Environmental Sciences, Cork, Ireland

${ }^{2}$ Trinity College Dublin, Department of Zoology, School of Natural Sciences, Dublin 2, Ireland

${ }^{3}$ Trinity Centre for Biodiversity Research, Trinity College Dublin, Dublin 2, Ireland

${ }^{4}$ Imperial College London, Silwood Park Campus, Department of Life Sciences, Buckhurst Road, Ascot SL5 7PY, United Kingdom

${ }^{5}$ School of Biology, Sir Harold Mitchell Building, Greenside Place, St Andrews, KY16 9TH, United Kingdom

Corresponding author: A. Kane, University College Cork, Cooperage Building, School of Biological Earth and Environmental Sciences, Cork, Ireland. E-mail: adam.kane@ucc.ie

Decision date: 30-Sep-2016

This article has been accepted for publication and undergone full peer review but has not been through the copyediting, typesetting, pagination and proofreading process, which may lead to differences between this version and the Version of Record. Please cite this article as doi: [10.1111/ecog.02817].

'This article is protected by copyright. All rights reserved.' 


\begin{abstract}
Despite its prevalence, the importance of scavenging to carnivores is difficult to ascertain in modern day forms and impossible to study directly in extinct species. Yet, there are certain intrinsic and environmental features of a species that push it towards a scavenging lifestyle. These can be thought of as some of the principal parameters in optimal foraging theory namely, encounter rate and handling time. We use these components to highlight the morphologies and environments that would have been conducive to scavenging over geological time by focusing on the dominant vertebrate groups of the land, sea and air. The result is a synthesis on the natural history of scavenging. The features that make up our qualitative scale of scavenging can be applied to any given species and allow us to judge the likely importance of this foraging behaviour.
\end{abstract}

Keywords: scavenging, carrion, vertebrates 


\section{Introduction}

Historically, food webs have classified most acts of carnivory as predation events (Wilson and Wolkovich 2011). This is clearly a mistaken view because of the existence of scavenging, a behaviour displayed by almost all carnivorous vertebrates (DeVault et al. 2003). Recent research has begun to redress this imbalance by recognising the prevalence of scavenging and its implications for trophic ecology across modern ecosystems (Pereira et al. 2014, Périquet et al. 2015). By increasing multichannel feeding and the number of food web links, scavenging can confer stability to an ecosystem (Moleón and Sánchez-Zapata 2015). Indeed, there is no discrete divide between predators and scavengers but rather a continuous gradient in terms of the proportion of carrion in the diet (Pereira et al. 2014). Even vultures, the canonical example of obligate scavengers, can hunt (Margalida et al. 2011). While it is relatively easy to determine whether a species engages in scavenging through observation, determining the proportion of carrion in the diet requires extensive behavioral data. This is because approaches such as stomach content and stable isotope analysis are unable to distinguish between scavenging and predation.

Unfortunately, the lack of direct behavioural data makes it even more difficult to discern scavenging from predation among extinct forms where it was surely exhibited by prehistoric vertebrate carnivores. Some simple heuristics can inform us whether or not the prey was scavenged, for instance, in cases where it was simply too large to have been killed by the ostensible predator (Pobiner 2008). But clearly, a scavenger does not only feed on dead animals too big for it to have hunted. 
There are other methods however, that can allow us to discern the most suitable morphologies, physiologies and environments for a scavenging lifestyle to prosper e.g. energetics models, comparative anatomy, palaeontology etc. (Shipman 1986, Ruxton and Houston 2003; Carbone et al. 2011). Yet, a synthesis describing the natural history of scavengers is absent from the literature. Here we rectify this shortcoming in charting the natural history of scavenging by assessing its potential among vertebrate groups past and present given their ecology, functional traits and the environmental context.

\subsection{The Challenges of Scavenging}

Species that rely on scavenging to sustain substantial portions of their diets must encounter a sufficient amount of carrion in order to meet their energetic demands. Once found, the scavenger must be able to out-compete any potential competitors and efficiently process the, increasingly decaying, carcass replete with invertebrates and micro-organism derived toxins (Ruxton et al. 2014). These characteristics can be assumed to be under evolutionary selection pressures for traits that increase carrion discovery and monopoly. Finally, the potential for scavenging, in either a species as a whole, or for individuals within a population, will also depend on the density, size, and quality of carcases produced, all of which are affected by complex ecosystem dynamics (Moleón et al. 2014b). Each of these facets are essentially the backbone of fundamental ecological theory and are the key parameters defined in functional response curves, namely encounter rate, handling time and prey availability (Jeschke et al. 2002). By considering scavenging in this context of optimal foraging we can identify the prerequisite attributes and processes required for the behaviour. This has enabled us to propose a qualitative scale of scavenging whereupon we can place a given vertebrate 
carnivore and assess the likely importance of carrion in its diet. We argue that such a scale could be valuable when behaviour cannot be observed directly, e.g. for extinct vertebrates.

\section{Encounter Rate}

All foraging processes depend on the encounter rate between consumer and resource. Locomotory speed, foraging time and detection radius all determine the encounter rate between a scavenger and the carcasses it is searching for and we would thus expect selection pressures to act on the various traits that govern these parameters. Selection might also drive a species to reduce its metabolic requirements so that it can survive long periods between meals, or expand a species' ability to process tissues or decaying flesh that might ordinarily be discarded. However, as we noted above, encounter rate is also determined by the productivity of the environment, and ultimately the rate at which carcasses are produced. Carcass production itself depends on factors such as predation, disease and scavenging itself. For instance, by consuming the majority of carrion, more prolific scavengers may deny a resource to their less prolific counterparts obliging the latter to hunt more, and thus, increase the amount of carrion (Moleón et al. 2014b).

\subsection{Metabolism}

Because of the ephemeral nature of carrion (DeVault et al. 2003, Ruxton and Houston 2004b) we expect adaptations that reduce energetic costs of maintenance to be selected for in scavengers as it would allow for longer inter-feeding periods. Extant reptiles possess an advantage here, in that over the course of a year their food requirements can be 30 times lower than an endotherm of equal size (Nagy 2005). DeVault and Krochmal 
(2002) suggest this is an avenue for scavenging in snakes because they "exhibit exceedingly low maintenance metabolisms, and most can survive on a few scant feedings per year. It is, therefore, possible for snakes to rely largely on infrequent, less energy-rich meals." In the same review the authors found occurrences of scavenging spread across five families of snakes and stated that this behaviour is "far more common than currently acknowledged."(DeVault and Krochmal 2002).

The same reasoning can be applied to crocodiles and their allies (Forrest 2003, Moleón et al. 2015). Carey et al. (1982) found that sharks, as ectotherms, have the ability to go weeks between meals because they focus on the energy-rich sections of carcasses (see Handling Time 3). Endotherms have also evolved physiological mechanisms that allow them to depress their otherwise high metabolic rates at certain times. For example, vultures who do so while resting at their roost and during periods of food deprivation, a problem that their large body size also helps to overcome (Bahat et al. 1998, Moleón et al. 2014b).

While it is difficult to infer the metabolisms of extinct species, similarities can still also be drawn. Many ectothermic groups such as sharks and bony fish were likely to benefit from the ability to bridge long time-spans between meals such as seen in snakes. In contrast, forms such as dinosaurs (Grady et al. 2014), pterosaurs (Wellnhofer 1991), some marine reptiles (Bernard et al. 2010) and some early mammals (Lovegrove 2016) have been proposed to have possessed at least partial endothermy, potentially requiring a higher intake of material in comparison to their ectothermic equivalents. However, such higher metabolic rates would also have increased the ability of such species to actively search for carrion. 


\subsection{Locomotion}

Compared to live prey, carrion is relatively unpredictable and ephemeral, (DeVault et al. 2003), which means scavenging depends more on the ability to efficiently move over larger areas than does predation. This generally requires an efficient transfer of metabolic energy into movement which relies on the animal's anatomy and physiology as well as the medium of the environment in which the animal is moving (i.e. aerial, aquatic or terrestrial). Perhaps the most efficient form of locomotion in vertebrates is found in flying species. Despite the energetic costs of flight, the most prolific modern, vertebrate scavengers are the old and the new world vultures. While powered flight is energetically expensive, species like vultures have evolved behavioural and anatomical features to exploit air currents using their large wingspans, allowing them to soar at a cost of only around 1.5 times their metabolic rate (Hedenstrom 1993, Duriez et al. 2014). By depending on thermal air flows these species can forage over vast ranges (Spiegel et al. 2013). An analogous mode of locomotion is also exploited by seabirds, who use strong ocean winds to search large areas of the oceans (Norberg 2012, Thaxter et al. 2012). While many species of seabird are likely primarily predators, it seems that albatrosses, who can range many hundreds of kilometres, take a substantial amount of carrion in their diet (Croxall and Prince 1994). This is typically in the form of squid carcasses, which float on the surface, allowing the birds to readily pluck their remains out of the water (Croxall and Prince 1994).

The groups from which these modern soaring birds arose, appeared during the Palaeocene (66 - 56 Million years ago (Mya); Jetz et al. 2012, Jarvis et al. 2014) and Cretaceous (145.5 - 65.5 Mya; Chiappe and Dyke 2006) respectively. However, soaring 
flight is likely to be far older than this with avian flight originating in the Late Jurassic (163.5 - 145 Mya) and vertebrate flight in the Late Triassic (235 - 201.3 Mya) coincident with the pterosaurs. Indeed, scavenging among pterosaurs has been hypothesised many times before (Witton and Naish 2008). Certain groups of these animals could reach enormous sizes (e.g. Azhdarchids with wingspans of 11 metres; Witton and Habib 2010) and, notably, appear to have engaged in soaring flight (Witton and Habib 2010). It seems probable that at least some of these extinct species used soaring as a means for scavenging (Witton 2013).

While soaring is perhaps the only viable means of locomotion that allows for scavenger to rely entirely on carrion (Ruxton and Houston 2004b), powered flight is still an efficient means of locomotion. Certainly, avian flight is cheaper per unit distance than either walking or running (Tucker 1975).

We know that many extant birds exist as facultative scavengers because storks, raptors and corvids all take substantial quantities of carrion in their diet (Mateo-Tomás et al. 2015). Similarly, we would expect that extinct species would also scavenge in a similar fashion depending on the efficiency of their flight. For example, early birds such as Archaeopteryx are predicted to have been poor, relatively inefficient fliers (Nudds and Dyke 2010) and so ill-suited to finding carrion. The importance of efficient flying over large areas may explain the lack of scavenging behaviour in bats as they are generally nocturnal, a time when they would receive no aid from convective air currents (Norberg 2012).

Similar to aerial species, aquatic scavengers have a locomotory benefit because water is a medium that is conducive to low-cost movement (Tucker 1975, Williams 1999). This 'This article is protected by copyright. All rights reserved.' 
has led some researchers to argue for the likelihood of an obligate scavenging fish (Ruxton and Houston 2004a, Ruxton and Bailey 2005).

Sharks are one likely candidate for general scavenging behaviors as their locomotion, which depends on large pectoral fins to generate lift as they swim, resembles that of the large soaring fliers. Many shark species have large foraging ranges (e.g. the great white sharks Carcharodon carcharias; Bruce et al. 2006) and it seems reasonable that they would use oceanographic currents to further reduce movement costs (Ruxton and Houston 2004a). In fact, facultative scavenging is seen in many selachian groups, including species of extant sharks like white sharks (known to feed on whale carcasses; Fallows et al. 2013), Greenland sharks (feeding on seals; Watanabe et al. 2012), and sixgill sharks (Anderson and Bell 2016). There is evidence too of scavenging in extinct species, where shark teeth have been found in the remains of dinosaurs, mosasaurs and Pliocene mysticete whales (5.3 - 3.6 Mya; Schwimmer et al. 1997, Ehret et al. 2009).

Interestingly, however, style of swimming in fishes does not significantly affect the cost of movement (Williams 1999). Hence, it is likely that many aquatic species with large ranges will encounter scavenging opportunities.

We might expect then that by combining an aquatic environment and an endothermic metabolism marine mammals would especially prosper as scavengers. Fossil pinnipeds and cetaceans from 60 Mya have transitional features indicative of their evolutionary trajectory to fully aquatic species (Williams 1999). But despite their movement away from land their energetic savings were negligible because the total cost incurred by a swimming marine mammal is high (Williams 1999). Indeed, the total energetic cost is similar to an equivalent terrestrial or aerial mammal (Williams 1999). This underscores 'This article is protected by copyright. All rights reserved.' 
the tradeoffs between the benefits of endothermy in terms of activity periods and the costs of maintaining such an energetically expensive system. That said, aquatic endotherms have and do scavenge. For instance, early whales such as Basilosaurus (38 36.5 Mya) seem to have fit into the same niche as killer whales (Orcinus orca) and we have some evidence for scavenging in both (Fahlke 2012, Whitehead and Reeves 2005).

Terrestrial environments are the most energetically costly in which to move (Tucker 1975). Unlike aerial and aquatic environments, support must be provided through the animal's posture. The early transition from a sprawling gait, seen in early tetrapods, to the more erect posture of synapsids and later dinosaurs and mammals, has often been supposed as conferring a huge advantage to the latter groups (Sullivan 2015). The purported advantages include benefits in terms of speed, efficiency, muscle effort and manoeuvrability (Sullivan 2015). Clearly, for a scavenger, an ability to efficiently cover an area at a high speed would increase the encounter rate with carrion. Despite being intuitive, Sullivan (2015) states most of the hypotheses in favour of this idea remain to be tested in the context of archosaur evolution. One noted consequence of a sprawling gait is the phenomenon known as Carrier's constraint such that the animal can't move and undergo coastal ventilation at the same time because the lateral movements impedes its lungs (Carrier 1987). The evolution of an upright posture has been offered as one of the primary mechanisms that allowed early archosaurs to overcome this constraint (Uriona and Farmer 2008).

Whatever the case, it is with the evolution of endothermy in the therapsid-mammal lineage (Clarke and Pörtner 2010) that terrestrial vertebrates would have gained the ability to range more widely, a vital component in seeking out carrion. Modern 
endothermic mammals can sustain longer periods of energetically expensive activity (Bennett and Ruben 1979) resulting in larger foraging ranges.

Today, terrestrial scavenging in mammals is probably best known in the African Savannah context where hyenas and lions can all take sizeable proportions of carrion in their diet (Pereira et al. 2014, Périquet et al. 2015). In the spotted hyena (Crocuta crocuta), striped hyena (Hyaena hyaena) and brown hyena (Hyaena brunnea) it can be over $90 \%$ (Jones et al. 2015). Most, if not all, vertebrate terrestrial carnivores take carrion to some extent (DeVault et al. 2003, Beasley et al. 2015, Pereira et al. 2014). The particular ability of hyenas to subsist on high proportions of carrion means we can use them as examples of efficient terrestrial scavengers to compare with other forms (Périquet et al. 2015). In terms of locomotion, they employ a characteristic "rocking horse gait" which allows them to cover great distances efficiently, loping at $10 \mathrm{~km} / \mathrm{hr}$ (Mills 1989, Jones et al. 2015). Such long-distance travel is apparent in many other cursorial predators (Pennycuick 1995, Janis and Figueirido 2014, Pereira et al. 2014). In contrast, big cats rely on ambush (Pennycuick 1995, Pereira et al. 2014). This difference means ambush predators tend to be more obligate hunters (Pereira et al. 2014). These insights allow us to compare extant terrestrial species to their prehistoric forebears given the dominance of mammalian carnivores since the Eocene (56-33.9 Mya) where the order split into the Caniforma and Feliforma (Van Valkenburgh 1987). To take one example, Anyonge (1996) found that Nimravides, a genus of sabretooth cat from the Miocence (10.3 - 5.3 Mya), were likely to have been ambush predators which would argue against them taking a lot of carrion. 
Of course, terrestrial animals can also move bipedally. Although the evolution of bipedal movement was significant in that it freed up the forelimbs for other purposes (e.g. climbing, tool-use, wing development etc.) it does not differ radically in cost from quadrupedal locomotion (Williams (1999), and references therein). For instance, Alexander (2004) shows that, in the case of humans, we are more economical than predicted while walking and less so while running according to predicted costs of terrestrial movement calculated by allometric scaling relationships. Our locomotory efficiency has fed into the question of where our ancestors placed on the hunterscavenger axis during the Plio-Pleistocene, which has been a matter of debate for years (Capaldo and Peters 1995, Domínguez-Rodrigo 2002). Ruxton and Wilkinson (2013) added to this debate with their argument that long distance endurance running was not an important feature of hominin scavenging but was instead used by humans for hunting prey by chasing them to exhaustion over large distances. Even when considering the use of weapons and social foraging, the authors argue that the high cost of running long distances would render it an unattractive foraging strategy for scavenging. Yet, it still may have been useful to signal the location of carrion to others.

Aside from humans and our allies, the best-known terrestrial bipeds are the dinosaurs and unsurprisingly, given their enduring appeal, the prevalence of scavenging has been extensively explored in the carnivorous theropods. These were the dominant terrestrial carnivores for most of the Mesozoic Era (252.17 - 66 Mya) and ranged from the chicken-sized to the whale-sized, all of which were bipedal. While the locomotory ability of theropods has been debated since their first inception, more recent studies have reconstructed them as relatively mobile animals (Pontzer et al. 2009). Despite some suggestions that larger species may have had some advantage in scavenging, 
partially due to the ability to search large areas (Ruxton and Houston 2003), more recent work has shown that the energetic demands of locomotion in such large forms meant scavenging was likely more prevalent in mid-sized theropods of approximately half a tonne (Kane et al. 2016).

\subsection{Sensory Detection}

As predicted by the importance of an increased encounter rate, known scavengers have evolved well-developed senses, with the visual and olfactory sensory systems most often associated with scavenging behavior. This is perhaps no surprise because sensory systems that rely on detecting signals associated with living animals, such as audioception, electroreception, thermoreception and echolocation will be limited in their ability to detect an already dead animal.

Apart from the basic capacity of these senses to detect carrion, how they function in different environments is also important. In the simplest case, the search space is a two dimensional plane (Pawar et al. 2012). If the scavenger itself is searching on the plane, as is so for terrestrial species, the detection range is simply defined by the radius of their sensory organs. Consequently, the ability to detect carrion can be seriously restricted for visually reliant, terrestrial species. They may overcome this restriction however, by using olfaction, which is less affected by the relief of the land. For example, hyenas have the ability to smell a rotting carcass $4 \mathrm{~km}$ away (Mills 1989), which exceeds the 500 m range deemed necessary by Ruxton and Houston (2004b) to be able to survive as a scavenger. 
Indeed, the olfactory senses of many extant (and in all probability extinct) carnivores meet this required distance, making scavenging feasible for most terrestrial carnivores (Farlow 1994, Mech and Boitani 2010). Among extinct species in particular, we can use the ratio of olfactory bulb to brain size to infer a preference for olfactory foraging (Zelenitsky et al. 2011). This approach was used by Zelenitsky et al. (2011) to hypothesise such a mode for the theropod dinosaur Bambiraptor and by Witmer and Ridgely (2009) for tyrannosaurs. The flying pterosaurs however, had tiny olfactory bulbs indicating this sense was not relied on (Witton 2013).

Species capable of flight have added an extra spatial dimension (i.e. the vertical component) to their sensory environment over land animals. This allows them to look down on a landscape where they are unencumbered by obstacles that would obstruct the view of a terrestrial scavenger. In this way they are effectively cheating the $2 \mathrm{D}$ system by gaining a bird's eye view which has obvious benefits in detecting carrion. Certainly, vultures are known to have impressive visual acuity, with one estimate indicating lappet-faced vultures (Torgos tracheliotus) are capable of detecting a 2 metre carcass over $10 \mathrm{~km}$ away (Spiegel et al. 2013). Eagles too are known to have highly developed vision (Reymond 1985). The flying pterosaurs also convergently evolved large orbits and optic lobes (Witton 2013). It follows that the evolution of flight allowed aerial animals to detect far more carrion than their terrestrial counterparts through vision (Lisney et al. 2013).

The terrestrial-olfaction, aerial-visual divide is not total though. Terrestrial species like hyenas and hominins exploit the efficiency of birds by looking to the skies for groups of vultures to follow to carrion (Jones et al. 2015, Ruxton and Wilkinson 2013). And many 
birds, e.g. turkey vultures (Cathartes aura), have well-developed olfactory systems (Lisney et al. 2013) which they use to forage in heavily forested areas where vision is limited (Houston 1986).

Although aquatic species also have a vertical component to their environment, they must contend with low-light levels where visual detection distances are far lower $(<100$ m) than they would be for air. As such, aquatic animals detect resources through chemoand mechanoreception more so than through vision (Ruxton and Houston 2004a). This is particularly relevant to sharks and aquatic snakes who are deemed as having the most suitable physiology for scavenging. A hypothesis put forth by Sazima and Strüssmann (1990) argued that chemical gradients in water would allow for a relatively easier detection of carrion by snakes. This gained some support from DeVault and Krochmal (2002), who found a preponderance of aquatic snake species in their review of this behaviour. Smell seems to be the primary means of carcass detection in sharks as well. Fallows et al. (2013) found that wind speed determined the number of sharks feeding at whale carcasses due to chemical stimuli from the carcasses being propagated through the water by the wind, indicating they were dependent on detecting the odours from the decaying whales.

\subsection{Carcass Availability}

\subsubsection{Abiotic effects}

The environmental influence on carcass availability is an aspect that greatly affects encounter rate. Aspects including, primary productivity, relief, and temperature will all affect scavenging tendency. Something as simple as the physical structure of the 
environment can have an impact, for example, snakes can access carrion in burrows that is otherwise inaccessible to other species (DeVault \& Krochmal 2002).

Ruxton and Houston (2004b) suggest an historic ecosystem with a productivity similar to the Serengeti could have supported an obligate mammalian or reptilian terrestrial scavenger. Indeed, in systems that were dominated by large ectothermic or mesothermic herbivore vertebrates, the same primary productivity would have supported a greater biomass, due to the scaling of mass with metabolic rate (McNab 2009). The upshot of this may have been a higher biomass of herbivores dying and offering scavenging opportunities (although these larger species may have also lived longer).

In fact, scavenging behaviour may have evolved on land as soon as the first terrestrial tetrapods emerged. Some of the earlier tetrapods tracks dating back to the early Middle Devonian (393.3 - 387.7 Mya) were found in intertidal environments (Niedzwiedzki et al. 2010). These environments are isolated from marine systems twice a day leaving potential carrion unexploited by marine vertebrates. Niedzwiedzki et al. (2010) suggest that these environments "would thus have allowed marine ancestors of tetrapods gradually to acquire terrestrial competence while accessing a new and essentially untouched resource."

The physical differences between water and air mean carcass availability is radically different between these environments (Beasley et al. 2012). For one, carcasses get moved around by water which results in a more diffuse signal being produced for would-be scavengers. Carcasses also tend to sink in water where they are no longer accessible to pelagic scavengers (Beasley et al. 2012) (although there may be a second floating stage due to the action of bacteria (Teather 1995)). Research has shown that an 'This article is protected by copyright. All rights reserved.' 
animal need only travel $36 \mathrm{~km}$ to encounter a fresh whale carcass (Smith and Baco 2003). The phenomenon of occasional bounties of carrion in the form of these whale falls has led some researchers to investigate if a scavenger could survive by seeking out these remains exclusively. Ruxton and Bailey (2005) argued that although this is energetically feasible it's ecologically unlikely. Any animal that could find such whale carcasses is unlikely to have ignored other types of carrion.

Although no aquatic species have ever exceeded the size of whales, some enormous animals have evolved in this environment before the evolution of cetaceans, including Leedsichthys, a bony fish from the Middle Jurassic (174.1 - 163.5 Mya) and the aquatic Mesozoic reptiles, the plesiosaurs, pliosaurs and ichtyosaurs, that could all exceed 15 metres in length (Ruxton 2011, Danise et al. 2014). So, despite being unlikely, the energetic feasibility of a marine scavenger that specialises on large carcasses has a long history.

Perhaps the greatest environmental driver of scavenging tendency is that of temperature which has a significant bearing on the availability, predictability and persistence of carrion. We know from the geological record that the Earth has undergone radical fluctuations in temperature over time. On land, there are a wide variety of vegetation types, from thickly forested areas to open grassland and the extent of this vegetation changes with season. To illustrate the point, a 10C increase in ambient temperature can double carcass decomposition rates (Parmenter and MacMahon 2009) and geological evidence indicates that the Mesozoic Earth was on average at least $6 \mathrm{C}$ warmer than now (Sellwood and Valdes 2006). In terms of specific habitats, it has been shown that 
decomposition is greater in warm and moist areas versus more xeric ones (Beasley et al. 2015).

The impacts these can have on scavengers have been empirically supported e.g. Beasley et al. (2015) who point to a series of studies showing how microbes and invertebrates benefit at higher temperatures to the detriment of vertebrate scavengers such that "above 20C vertebrates were able to detect and consume only $19 \%$ of small-mammal carcasses, whereas at temperatures below $18 \mathrm{C}$, vertebrates consumed $49 \%$ of carcasses". Spikes in temperature can intensify droughts causing mass mortality events which result in relatively predictable peaks in carrion availability (Kendall et al. 2014). The Earth has also undergone a series of ice ages of various spatio-temporal extent (Diedrich 2012) and modern terrestrial settings that experience sub-zero conditions can act as a microcosm to show the effect extreme cold can have on scavenging. As with extremely hot conditions, extreme cold can result in mass mortality, again, providing carrion for the scavenging community (Pereira et al. 2014). Yet, freezing carcasses can become too hard to consume by most vertebrate carnivores (Selva et al. 2003).

\subsubsection{Biotic effects}

Foragers do not exist in isolation and we know from field observations that scavengers can scrounge on the discoveries of other carnivores. This sort of facilitation occurs across a range of scavengers, in the air and on the ground (Kane et al. 2014, Jones et al. 2015).

In flight, birds are able to gather a wealth of information from other foragers, be they conspecifics or otherwise (Jackson et al. 2008, Kane et al. 2014, Moleón et al. 2014b). 
Again, returning to vultures, the genus Gyps consists of highly social and colonially nesting species (Fernández-Bellon et al. 2015). These behaviours allow them to forage far more efficiently because one bird can scrounge information on the location of food from another successful forager (Cortés-Avizanda et al. 2014). Information transfer of this kind is typically inadvertent and as a consequence no complex social interactions are required, simply the ability to recognise a successful forager. Thus, given pterosaurs seem to have cohabited in large numbers (Witton 2013), and the theoretical benefits this can have for social foraging in birds (Dermody et al. 2011), it seems probable that scrounging behaviours were seen in the flying pterosaurs as well.

This type of facilitation then increases the encounter rate of the facilitated species and can increase the population size of the latter (Moleón et al. 2014b). This higher population of predators may take more prey and so produce more carcasses. Conversely, by feeding on carcasses, predators may hunt less because they are sated by carrion, ultimately reducing predation risk on their prey base (Moleón et al. 2014b).

Modern scavenging assemblages are known to be influenced by carcass size (Moleón et al. 2015). Larger carcasses tend to last longer and also present a more conspicuous target for a foraging scavenger which results in more species attending them (Moleón et al. 2015). This will have had implications for extinct assemblages because body size distributions vary across different environments but also across time. O'Gorman and Hone (2012) showed Mesozoic faunal distributions may have been skewed towards larger species. Similarly, the megafauna of the Pleistocene (Doughty et al. 2013) would have produced large carcasses. As a result, the scavenger assemblages during this time would have been particularly diverse. 


\section{Handling Time}

Since the food a scavenger depends upon is not dispatched directly, often the most easily accessible and choicest components of the carcass will be missing owing to the activity of predators and other scavengers, or, if present, will be subject to decay as well as competition. So being able to overcome competitors and maximise the nutrient gain from the remnants are all essential parts of carcass handling time.

\subsection{Competition}

Large body size has substantial advantages in agonistic interactions (Ruxton and Houston 2004b, Moleón et al. 2014b, Pereira et al. 2014). For instance, lions can acquire much of their carrion through kleptoparasitism of hyena kills (Trinkel and Kastberger 2005, Pereira et al. 2014, Périquet et al. 2015). This line of reasoning suggests that some theropod dinosaurs, who could get up to 15 tonnes, would have easily monopolised a carcass (Weishampel et al. 2004) provided they could find them efficiently (Kane et al. 2016).

We would expect this trait to be selected for even in the case of weight-constrained, scavenging fliers. This is true for many vultures and other major avian scavengers such as albatrosses who can have body masses in excess of $10 \mathrm{~kg}$ and represent some of the heaviest bird species capable of flight (Weimerskirch 1992, Ferguson-Lees and Christie 2001, Donázar et al. 2002). Indeed, such is the competitive advantage held by vultures over other facultative scavenging birds that temporal niche partitioning at the carcass has evolved (Kendall 2013, Kane et al. 2014, Moreno-Opo et al. 2016). Additionally, many pterosaurs were far bigger again, with estimated body masses of over $200 \mathrm{~kg}$ in 
the Azhdarchids (Witton and Habib 2010). Although Witton and Naish (2008) argued that neck inflexibility and straight, rather than hooked jaw morphology points against Azhdarchids being as well adapted as vultures to scavenging, their terrestrial proficiency indicates they would have been comfortable foraging on the ground. Extant Marabou Storks (Leptoptilos crumeniferus) have a comparable morphology and are noted facultative scavengers (Monadjem et al. 2012) so it is reasonable to believe that these pterosaurs behaved similarly.

By contrast, extant bats seem poorly equipped to deal with competitors. Their poor terrestrial ability, small size and cost of movement on the ground would count against them while attempting to fend off other species at a carcass (Riskin et al. 2006, Voigt et al. 2012).

Smaller species can compensate for a lack of individual body size by weight of numbers in competitive interactions. This is true for a host of notable scavengers, such as vultures, early hominins and hyenas, who can and could dominate larger competitors provided they substantially outnumber(ed) them (Kane et al. 2014, Trinkel and Kastberger 2005, Ruxton and Wilkinson 2013).

Direct confrontation can be circumvented by certain behavioural adaptations. The evolution of nocturnal behaviour in some mammals, for instance, has been put forth as an adaptation to reduce competition with the exclusively diurnal vultures as well as with other larger predators (Gittleman 2013, Moleón et al. 2014b, Pereira et al. 2014). In areas absent of vultures such as the Arctic, terrestrial carnivores like bears and wolves take more carrion (DeVault et al. 2003) Thus, in the Palaeozoic, the absence of flying 
vertebrate competitors may have permitted terrestrial forms to take in a higher proportion of carrion in their diet.

In addition to fending off other vertebrates, scavengers also have to contend with competition from invertebrates and micro-organisms, the latter of which may require a specialised physiology to deal with. Although the findings of Shivik (2006) that "evolutionary pressures favor detection maximizers relative to toxification minimizers in competitive interactions for carcasses." appear sound, the fact remains that overcoming micro-organism toxins is still a beneficial adaptation to any scavenger. Avian scavengers have evolved incredibly acidic stomachs that allow them to consume and process putrefied flesh with no ill effects (Houston and Cooper 1975, Roggenbuck et al. 2014). This adaptation is not restricted to vultures though, Grémillet et al. (2012) showed wandering albatrosses (Diomedea exulans; so-called "vultures of the seas") had an average stomach $\mathrm{pH}$ of 1.5 , which enables them to consume fisheries discards and squid carcasses.

There is also evidence of selection for "toxification minimizers" beyond birds among the ectotherms. From our earlier arguments we know that ecthotherms are limited in their ability to find carrion as quickly as endotherms. These later arrivers would thus benefit especially from well-developed detoxifying apparatus. Shivik (2006) suggests that "specialized oral structures in snakes may have evolved under pressures associated with scavenging." Moreover, some researchers have charted an evolutionary course from basal fossorial snakes to modern terrestrial species by way of a scavenging intermediate (Bauchot 2006). However, snake venom is primary associated with predation in extant species suggesting that if venom played such a role aiding digestion 
of discovered carcasses in extinct species it is no longer its main function (Casewell et al. 2013). In water, by contrast, competition with micro-organisms is significantly reduced because of the high pressures and low temperatures (Beasley et al. 2012).

\subsection{Facilitation}

In contrast to competitive interactions, there are facilitatory processes at play between vertebrate scavengers that can benefit the facilitated species. Rather than there being a random assortment of species at a carcass, scavenging assemblages tend to be nested (Selva and Fortuna 2007). This means the species that feed on the majority of carcasses, for example vultures, are a subset of a larger community which comprises hyenas, jackals, raptors etc. (Sebastián-González et al. 2016). We noted above that this often results in an increased encounter rate but it can also reduce handling time for the species that follow. Some examples of reduced handling time include vultures, hyenas and wolves opening the tough hides of ungulate carcasses that would otherwise be inaccessible to corvids and smaller mammalian carnivores (Selva et al. 2003, Moleón et al. 2015). Unfortunately, these interactions are particularly difficult to detect in extinct species.

\subsection{Food Processing}

Another vital component of carrion handling time is the ability to maximise the energy gain from the remains while reducing the energetics of doing so. At whale carcasses, white and blue sharks are known to preferentially feed on the blubber layer (Long and Jones 1996). Blubber is an energy rich portion of the carcass that can allow a shark to survive for 1.5 months on $30 \mathrm{~kg}$ of the material (Carey et al. 1982). 
On land many scavengers utilize late-stage carcass material that is less subject to decomposition and may be unavailable to other competitors, for example bone.

Osteophagy is known across a range of terrestrial carnivores and given that some fatrich mammalian bones have an energy density $(6.7 \mathrm{~kJ} / \mathrm{g})$ comparable with that of muscle tissue, it makes skeletal remains an enticing resource (Brown 1989). Within mammals, this ability reached its zenith among hyenas with the evolution of the estimated $110 \mathrm{~kg}$ Pachycrocuta brevirostris during the Pliocene (3.6 - 2.58 Mya; Palmqvist et al. 2011). Indeed, their extinction has been blamed on the decline of sabretooth cats (Machairodontinae), because the unique skull morphology of the latter meant they would leave a large amount of food on a carcass for would-be scavengers (Palmqvist et al. 2011; note, however that the inability of these cats to deal with bone may be overstated; Binder and Van Valkenburgh 2010). Earlier in the evolution of mammals, the bone-crushing dogs that evolved during the Oligocene (Borophaginae; 33.9 - 23.03 Mya) have also been compared to hyenas in terms of their feeding ecology (Van Valkenburgh et al. 2003, Martín-Serra et al. 2016).

In Mesozoic systems some large theropod dinosaurs had a morphology indicative of an ability to process bone (e.g. the robust skull and dentition of Tyrannosaurus rex; Hone and Rauhut 2010). There is direct evidence that T. rex did this in the form of distinctive wear marks on its tooth apices (Farlow and Brinkman 1994, Schubert and Ungar 2005) and the presence of bone fragments in its coprolites (Chin et al. 1998). The animal also had an enormous bite force, with one estimate putting it at 57000 Newtons (Bates and Falkingham 2012) which would have been powerful enough to break open skeletons (Rayfield et al. 2001). Osteophagy may have been even more viable during the Mesozoic era as well because of the skewed body mass distribution of herbivores 
towards larger sizes (O'Gorman and Hone 2012). When we couple this with the fact that skeletal mass scales greater than linearly with body mass (Prange et al. 1979) there would have been a lot of bone material to consume in the environment provided an animal had the biology to process it (Chure and Fiorillo 1997).

Despite not having the anatomical ability to break open bone, the bearded vulture (Gypaetus barbatus) has evolved a technique whereby it drops long bones from a height, splintering them on the rocks below which allows them to feed (Margalida 2008). Similarly, early hominins developed the ability to craft tools for breaking open bones (Blasco et al. 2014). A recent study investigating potential scavenging opportunities for hominins in Kenya found that, in addition to skeletal material, there is a substantial amount of scavengeable meat left on predated remains; sufficient to sustain the requirements of an adult male Homo erectus (Pobiner 2015). In some historical hominin-inhabited areas there were higher populations of felids compared to hyenids. Again, this is significant because hyenas are likely to have left far less flesh on a carcass than a felid such as a sabretooth, enabling contemporaneous hominins to benefit (Pobiner 2015). The use of tools and the cooperative nature of hominins meant they could likely get a substantial part of their energetic requirements through scavenging depending on their environment (Moleón et al. 2014a).

On the ground, and despite the advantages of social resource defence, the competitive ability of even the largest flying bird is radically diminished in their interactions with mammalian competitors, and as such they tend to consume carrion rapidly. Houston (1974) observed a group of Gyps vultures consuming all of the soft tissue from a $50 \mathrm{~kg}$ Grant's gazelle (Nanger granti) in eight minutes. Their serrated tongues and hooked 
bills enable them to achieve this feat (Houston and Cooper 1975). Aside from raptors, the specialised beaks of many modern bird lineages tends to hinder their ability to eat meat which is in contrast to the first lineages that did not have this feature (Martyniuk 2012). As Martyniuk (2012) notes, this skull morphology of early birds indicates they were predominantly carnivorous, implying scavenging was a live opportunity compared to many of their descendants. Among the pterosaurs, Witton (2013) makes the case that the istiodactyl pterosaurs were the most likely scavengers of this group based on their potential handling time. Their skull morphologies are indicative of animals that were suited to removing large amounts of flesh from an immobile foodstuff (Witton 2013).

Again, we can draw a comparison with species that are lacking in these features. Despite readily eating carrion in captivity, cheetahs (Acinonyx jubatus) and African Wild Dogs (Lycaon pictus) rarely do so in the wild because they are subordinate to many of the mammalian competitors they coexist with (Pereira et al. 2014). Extant bats are poorly equipped when it comes to feeding on carrion; the larger forms are typically frugivores and therefore lack the adaptations for digesting meat, while the smaller carnivorous bats are mainly found in the microbats, which are insectivorous (Aguirre et al. 2003). That said, Necromantis (“death-eater"), a large bat from the middle to late Eocene (56 - 33.9 Mya) had a robust cranio-mandibular morphology, and is a likely candidate for an extinct scavenging bat (Weithofer 1887, Hand et al. 2012).

\section{Conclusion}

As is often the case in science, the present provides the key to the past. The animals of today, while often different (sometimes radically so) to their ancestors, can be used to make informed comparisons to extinct species. We have used this approach to give 
insight into the drivers of scavenging across vertebrates through time. In common with any other forager be they grazer, browser or predator, scavengers past and present have had to balance their energetic costs with the gains of food. The main factors we considered namely, encounter rate and handling time can be used to create a scale of scavenging whereupon any species can be placed in order to predict the qualitative importance of carrion in it diet. We hope this approach will be useful in the effort to explore this most understudied of feeding ecologies.

\section{Acknowledgments}

Thanks to Natalie Cooper for highlighting the potential for this review, and to Ara Monadjem and Deirdre McClean for their comments on the manuscript. AK was funded by the Irish Research Council GOIP/2015/81, KH was funding by Science Foundation Ireland. T.G. acknowledges support from European Research Council under the European Union's Seventh Framework Programme (FP/2007-2013)/ERC Grant Agreement number 311092 awarded to Martin D. Brazeau. We also thank Marcos Moleón and two other anonymous reviewers for very perceptive and helpful feedback on a previous version.

\section{Conflict of Interest Statement}

We declare no conflict of interest. 


\section{References}

Aguirre, L. et al. 2003. The implications of food hardness for diet in bats. - Funct Ecol 17: 201-212.

Alexander, R. 2004. Bipedal animals, and their differences from humans. - J Anat 204: 321-330.

Anderson, G. S. and Bell, L. S. 2016. Impact of marine submergence and season on faunal colonization and decomposition of pig carcasses in the Salish sea. PloS one 11: e0149107.

Anyonge, W. 1996. Locomotor behaviour in plio-pleistocene sabre-tooth cats: a biomechanical analysis. - J Zool 238: 395-413.

Bahat, O. et al. 1998. Nocturnal variation in body temperature of griffon vultures. Condor: $168-171$.

Bates, K. and Falkingham, P. 2012. Estimating maximum bite performance in Tyrannosaurus rex using multi-body dynamics. - Biol Letters 8: 660-664.

Bauchot, R. 2006. Snakes: a natural history. - Sterling Publishing Company, Inc. New York, USA

Beasley, J. et al. 2015. Ecological role of vertebrate scavengers. - In: Benbow, M. E. et al. (eds.), Introduction to Carrion Ecology, Evolution, and Their Applications, chap. 6. CRC Press, Boca Raton, Florida, USA, pp. 107-128.

Beasley, J. C. et al. 2012. Carrion cycling in food webs: comparisons among terrestrial and marine ecosystems. - Oikos 121: 1021-1026.

Bennett, A. F. and Ruben, J. A. 1979. Endothermy and activity in vertebrates. Science 206: 649-654.

Bernard, A. et al. 2010. Regulation of body temperature by some mesozoic marine reptiles. -

Science 328: 1379-1382.

Binder, W. J. and Van Valkenburgh, B. 2010. A comparison of tooth wear and breakage in rancho 261.

la brea sabertooth cats and dire wolves across time. - J Vertebr Paleontol 30: 255- 
Blasco, R. et al. 2014. Breaking bones to obtain marrow: A comparative study between percussion by batting bone on an anvil and hammerstone percussion. Archaeometry 56: 1085-1104.

Brown, C. J. 1989. A study of the Bearded Vulture Gypaetus barbatus in southern Africa. Ph.D. thesis, University of Natal (Pietermaritzburg).

Bruce, B. et al. 2006. Movements and swimming behaviour of white sharks (Carcharodon carcharias) in Australian waters. - Mar Biol 150: 161-172.

Capaldo, S. D. and Peters, C. R. 1995. Skeletal inventories from wildebeest drownings at lakes

masek and ndutu in the serengeti ecosystem of tanzania. - J Archaeol Sci 22: $385-408$.

Carbone, C. et al. 2011. Intra-guild competition and its implications for one of the biggest terrestrial predators, Tyrannosaurus rex. - Proc. R. Soc. B 278: 2682-2690.

Carey, F. G. et al. 1982. Temperature and activities of a white shark, Carcharodon carcharias. - Copeia: 254-260.

Carrier, D. R. 1987. The evolution of locomotor stamina in tetrapods: circumventing a mechanical constraint. - Paleobiology: 326-341.

Casewell, N. R. et al. 2013. Complex cocktails: the evolutionary novelty of venoms. Trends

Ecol Evol 28: 219-229.

Chiappe, L. M. and Dyke, G. J. 2006. The early evolutionary history of birds. - J

Palaeontological Society of Korea 22: 133-151.

Chin, K. et al. 1998. A king-sized theropod coprolite. - Nature 393: 680-682.

Chure, D. and Fiorillo, A. 1997. One big al to go and hold the mayo: evidence of scavenging of a specimen of Allosaurus from the Morrison formation (late Jurassic) of Wyoming. - J Vertebr Paleontol 17: 38A.

Clarke, A. and Pörtner, H.-O. 2010. Temperature, metabolic power and the evolution of endothermy. - Biol Rev 85: 703-727.

Cortés-Avizanda, A. et al. 2014. Bird sky networks: How do avian scavengers use social information to find carrion? - Ecology 95: 17991808.

Croxall, J. P. and Prince, P. A. 1994. Dead or alive, night or day: how do albatrosses catch squid? - Antarct Sci 6: 155-162.

'This article is protected by copyright. All rights reserved.' 
Danise, S. et al. 2014. Ecological succession of a Jurassic shallow-water ichthyosaur fall. - Nat Comm 5.

Dermody, B. et al. 2011. The evolutionary pathway to obligate scavenging in Gyps vultures. -

PLOS ONE 6: e24635.

DeVault, T. L. and Krochmal, A. R. 2002. Scavenging by snakes: an examination of the literature.

- Herpetologica 58: 429-436.

DeVault, T. L. et al. 2003. Scavenging by vertebrates: behavioral, ecological, and evolutionary perspectives on an important energy transfer pathway in terrestrial ecosystems. - Oikos 102: 225-234.

Diedrich, C. G. 2012. Cave bear killers and scavengers from the last ice age of central europe:

feeding specializations in response to the absence of mammoth steppe fauna from mountainous regions. - Quatern Int 255: 59-78.

Domínguez-Rodrigo, M. 2002. Hunting and scavenging by early humans: the state of the debate. - J World Prehist 16: 1-54.

Donázar, J. A. et al. 2002. Effects of forestry and other land-use practices on the conservation of cinereous vultures. - Ecol Appl 12: 1445-1456.

Doughty, C. E. et al. 2013. The legacy of the pleistocene megafauna extinctions on nutrient availability in amazonia. - Nat Geosci 6: 761-764.

Duriez, O. et al. 2014. How cheap is soaring flight in raptors? a preliminary investigation in freely-flying vultures. - PLOS One 9: e84887.

Ehret, D. J. et al. 2009. Caught in the act: trophic interactions between a 4-millionyear-old white shark (Carcharodon) and mysticete whale from Peru. - Palaios 24: 329-333.

Fahlke, J. M. 2012. Bite marks revisited-evidence for middle-to-late eocene Basilosaurus isis predation on Dorudon atrox (both cetacea, basilosauridae). - Palaeontol Electron 15: $32 \mathrm{~A}$.

Fallows, C. et al. 2013. White sharks (Carcharodon carcharias) scavenging on whales and its potential role in further shaping the ecology of an apex predator. - PloS one 8: e60797. 
Farlow, J. and Brinkman, D. 1994. Wear surfaces on the teeth of tyrannosaurs. In: Dino Fest; Proceedings of a Conference for the General Public. Palaeontological Society Special Publications, vol. 7. pp. 165-175.

Farlow, J. O. 1994. Speculations about the carrion-locating ability of tyrannosaurs. Hist

Biol 7: 159-165.

Ferguson-Lees, J. and Christie, D. A. 2001. Raptors of the world. - Houghton Mifflin Harcourt, USA

Fernández-Bellon, D. et al. 2015. Density-dependent productivity in a colonial vulture at two spatial scales. - Ecology 97: 406-416.

Forrest, R. 2003. Evidence for scavenging by the marine crocodile Metriorhynchus on the carcass of a plesiosaur. - P Geologists Assoc 114: 363-366.

Gittleman, J. L. 2013. Carnivore behavior, ecology, and evolution. - Springer Science $\&$ Business

Media.

Grémillet, D. et al. 2012. Vultures of the seas: hyperacidic stomachs in wandering albatrosses as an adaptation to dispersed food resources, including fishery wastes. PLOS One 7: e37834.

Hand, S. et al. 2012. Necromantis weithofer, 1887, large carnivorous middle and late Eocene bats from the French quercy phosphorites: new data and unresolved relationships. - In: Gunnell, G. F. and Simmons, N. B. (eds.), Evolutionary History of Bats. Cambridge University Press, pp. 210-251.

Hedenstrom, A. 1993. Migration by soaring or flapping flight in birds: the relative importance of energy cost and speed. - Philos T Roy Soc B 342: 353-361.

Hone, D. W. and Rauhut, O. W. 2010. Feeding behaviour and bone utilization by theropod dinosaurs. - Lethaia 43: 232-244.

Houston, D. 1974. The role of griffon vultures Gyps africanus and Gyps ruppellii as scavengers. - J Zool 172: 35-46.

Houston, D. C. 1986. Scavenging efficiency of turkey vultures in tropical forest. - The Condor 88:

$318-323$.

Houston, D. C. and Cooper, J. 1975. The digestive tract of the whiteback griffon vulture and its role in disease transmission among wild ungulates. - J Wildlife Dis 11: 306-313. 
Jackson, A. L. et al. 2008. The effect of social facilitation on foraging success in vultures: a modelling study. - Biol Letters 4: 311-313.

Janis, C. M. and Figueirido, B. 2014. Forelimb anatomy and the discrimination of the predatory behavior of carnivorous mammals: The thylacine as a case study. J Morphol 275: 1321-1338.

Jarvis, E. D. et al. 2014. Whole-genome analyses resolve early branches in the tree of life of modern birds. - Science 346: 1320-1331.

Jeschke, J. M. et al. 2002. Predator functional responses: discriminating between handling and digesting prey. - Ecol Monogr 72: 95-112.

Jetz, W. et al. 2012. The global diversity of birds in space and time. - Nature 491: $444-448$.

Jones, S. et al. 2015. Ecology of african carrion. - In: Benbow, M. E. et al. (eds.), Introduction to Carrion Ecology, Evolution, and Their Applications, chap. 6. CRC Press, Boca Raton, Florida, USA, pp. 461-494.

Kane, A. et al. 2014. Vultures acquire information on carcass location from scavenging eagles. - Proc. R. Soc. B 281.

Kane, A. et al. 2016. Body size as a driver of scavenging in theropod dinosaurs. -Am Nat 187.

Kendall, C. J. 2013. Alternative strategies in avian scavengers: how subordinate species foil the despotic distribution. - Behav Ecol Sociobiol 67: 383-393.

Kendall, C. J. et al. 2014. African vultures don't follow migratory herds: scavenger habitat use is not mediated by prey abundance. - PLOS One 9: e83470.

Lisney, T. J. et al. 2013. Comparison of eye morphology and retinal topography in two species of new world vultures (aves: Cathartidae). - The Anatomical Record 296: 1954-1970.

Long, J. and Jones, E. 1996. White shark predation and scavenging on cetaceans in the eastern north Pacific Ocean. - In: Klimley, P. and Jones, E. (eds.), Great white sharks: the biology of Carcharodon carcharias, chap. 27. New York Academic Press, USA, pp. 293-307.

Lovegrove, B. G. 2016. A phenology of the evolution of endothermy in birds and mammals. -

Biol Rev.

Margalida, A. 2008. Bearded vultures (Gypaetus barbatus) prefer fatty bones. Behav Ecol Sociobiol 63: 187-193. 
Margalida, A. et al. 2011. Scavenger turned predator: European vultures' altered behaviour. -

Nature 480: 457-457.

Martín-Serra, A. et al. 2016. In the pursuit of the predatory behavior of borophagines (mammalia, carnivora, canidae): Inferences from forelimb morphology. - J Mamm Evol: 1-13.

Martyniuk, M. P. 2012. A Field Guide to Mesozoic Birds and Other Winged Dinosaurs. - Pan Aves.

USA.

Mateo-Tomás, P. et al. 2015. From regional to global patterns in vertebrate scavenger communities subsidized by big game hunting. - Divers Distrib 21: 913-924.

McNab, B. K. 2009. Resources and energetics determined dinosaur maximal size. - P Natl Acad Sci USA 106: 12184-12188.

Mech, L. D. and Boitani, L. 2010. Wolves: behavior, ecology, and conservation. University of Chicago Press, USA.

Mills, M. 1989. The comparative behavioral ecology of hyenas: the importance of diet and food dispersion. - In: Carnivore behavior, ecology, and evolution. Springer, pp. 125-142.

Moleón, M. et al. 2014a. Humans and scavengers: The evolution of interactions and ecosystem services. - BioScience 64: 394-403.

Moleón, M. et al. 2014b. Inter-specific interactions linking predation and scavenging in terrestrial vertebrate assemblages. - Biol Rev.

Moleón, M. et al. 2015. Carcass size shapes the structure and functioning of an African scavenging assemblage. - Oikos 124: 1391-1403.

Moleón, M. and Sánchez-Zapata, J. A. 2015. The living dead: Time to integrate scavenging into ecological teaching. - BioScience : biv101.

Monadjem, A. et al. 2012. Survival and population dynamics of the marabou stork in an isolated population, Swaziland. - PLOS ONE 7: e46434.

Moreno-Opo, R. et al. 2016. Behavioral coexistence and feeding efficiency drive niche partitioning in european avian scavengers. - Behav Ecol: arw010.

Nagy, K. A. 2005. Field metabolic rate and body size. - J Exp Biol 208: 1621-1625.

'This article is protected by copyright. All rights reserved.' 
Niedzwiedzki, G. et al. 2010. Tetrapod trackways from the early middle Devonian period of Poland.

- Nature 463: 43-48.

Norberg, U. M. 2012. Vertebrate flight: mechanics, physiology, morphology, ecology and evolution, vol. 27. - Springer Science \& Business Media.

Nudds, R. L. and Dyke, G. J. 2010. Narrow primary feather rachises in Confuciusornis and

Archaeopteryx suggest poor flight ability. - Science 328: 887-889.

O'Gorman, E. J. and Hone, D. W. E. 2012. Body size distribution of the dinosaurs. Plos ONE 7: e51925.

Palmqvist, P. et al. 2011. The giant hyena Pachycrocuta brevirostris : modelling the bone-cracking behavior of an extinct carnivore. - Quatern Int 243: 61-79.

Parmenter, R. R. and MacMahon, J. A. 2009. Carrion decomposition and nutrient cycling in a semiarid shrub-steppe ecosystem. - Ecol Monogr 79: 637-661.

Pawar, S. et al. 2012. Dimensionality of consumer search space drives trophic interaction strengths.

- Nature 486: 485-489.

Pennycuick, C. 1995. Energy costs of locomotion and the concept of "foraging radius". - In: Sinclair, A. R. E. and Norton-Griffiths, M. (eds.), Serengeti: dynamics of an ecosystem, chap. 7. University of Chicago Press, USA, pp. 164 18.

Pereira, L. M. et al. 2014. Facultative predation and scavenging by mammalian carnivores:

seasonal, regional and intra-guild comparisons. - Mammal Rev 44: 44-55.

Périquet, S. et al. 2015. The lion king and the hyaena queen: large carnivore interactions and coexistence. - Biol Rev 90: 1197-1214.

Pobiner, B. 2008. Paleoecological information in predator tooth marks. - J Taphon 6: 373-397.

Pobiner, B. L. 2015. New actualistic data on the ecology and energetics of hominin scavenging opportunities. - J Hum Evol 80: 1-16.

Pontzer, H. et al. 2009. Biomechanics of running indicates endothermy in bipedal dinosaurs. - Plos ONE 4: e7783.

'This article is protected by copyright. All rights reserved.' 
Prange, H. D. et al. 1979. Scaling of skeletal mass to body mass in birds and mammals. - Am Nat 113: 103-122.

Rayfield, E. J. et al. 2001. Cranial design and function in a large theropod dinosaur. Nature 409:

1033-1037.

Reymond, L. 1985. Spatial visual acuity of the eagle Aquila audax: a behavioural, optical and anatomical investigation. - Vision Res 25: 14771491.

Riskin, D. K. et al. 2006. Terrestrial locomotion of the new zealand short-tailed bat Mystacina tuberculata and the common vampire bat Desmodus rotundus. J Exp Biol 209: 1725-1736.

Roggenbuck, M. et al. 2014. The microbiome of new world vultures. - Nat Comm 5.

Ruxton, G. D. 2011. Zoology: Why are whales big? - Nature 469: 481-481.

Ruxton, G. D. and Bailey, D. M. 2005. Searching speeds and the energetic feasibility of an obligate whale-scavenging fish. - Deep Sea Res Pt I 52: 1536-1541.

Ruxton, G. D. and Houston, D. C. 2003. Could Tyrannosaurus rex have been a scavenger rather than a predator? an energetics approach. - Proc. R. Soc. B 270: 731-733.

Ruxton, G. D. and Houston, D. C. 2004a. Energetic feasibility of an obligate marine scavenger. - Mar Ecol Prog Ser 266: 59-63.

Ruxton, G. D. and Houston, D. C. 2004b. Obligate vertebrate scavengers must be large soaring fliers. - J Theor Biol 228: 431-436.

Ruxton, G. D. and Wilkinson, D. M. 2013. Endurance running and its relevance to scavenging by early hominins. - Evolution 67: 861-867.

Ruxton, G. D. et al. 2014. Why fruit rots: theoretical support for Janzen's theory of microbe-macrobe competition. - Proc. R. Soc. B 281: 20133320.

Sazima, I. and Strüssmann, C. 1990. Necrofagia em serpentes brasileiras: exemplos e previsões. - Revista Brasileira de Biologia 50: 463-468.

Schubert, B. W. and Ungar, P. S. 2005. Wear facets and enamel spalling in tyrannosaurid dinosaurs. - Acta Palaeontol Pol 50: 93-99.

Schwimmer, D. R. et al. 1997. Scavenging by sharks of the genus squalicorax in the late Cretaceous of North America. - Palaios: 71-83. 
Sebastián-González, E. et al. 2016. Nested species-rich networks of scavenging vertebrates support

high levels of interspecific competition. - Ecology 97: 95-105.

Sellwood, B. W. and Valdes, P. J. 2006. Mesozoic climates: General circulation models and the rock record. - Sediment Geol 190: 269-287.

Selva, N. and Fortuna, M. A. 2007. The nested structure of a scavenger community. - Proc. R. Soc. B 274: 1101-1108.

Selva, N. et al. 2003. Scavenging on european bison carcasses in bialowieza primeval forest (eastern poland). - Ecoscience 10: 303-311.

Shipman, P. 1986. Scavenging or hunting in early hominids: theoretical framework and tests. Am Anthropol 88: 27-43.

Shivik, J. A. 2006. Are vultures birds, and do snakes have venom, because of macro-and microscavenger conflict? - BioScience 56: 819-823.

Smith, C. R. and Baco, A. R. 2003. Ecology of whale falls at the deep-sea floor. - Oceanogr mar biol 41: 311-354.

Spiegel, O. et al. 2013. Factors influencing foraging search efficiency: why do scarce lappet-faced vultures outperform ubiquitous white-backed vultures? -Am Nat 181: E102-E115.

Spivey, R. et al. 2014. Analysing the intermittent flapping flight of a manx shearwater, Puffinus puffinus, and its sporadic use of a wave-meandering wingsailing flight strategy. - Prog Oceanogr 125: 62-73.

Sullivan, C. 2015. Evolution of hind limb posture in Triassic archosauriforms. - In: Dial, K. et al. (eds.), Great Transformations in Vertebrate Evolution, chap. 7. University of Chicago Press, USA, pp. 107-124.

Teather, R. G. 1995. Encyclopedia of Underwater Investigations. Best Publishing Company, Flagstaff, Arizona, USA.

Thaxter, C. B. et al. 2012. Seabird foraging ranges as a preliminary tool for identifying candidate marine protected areas. - Biol Conserv 156: 53-61.

Trinkel, M. and Kastberger, G. 2005. Competitive interactions between spotted hyenas and lions in the etosha national park, namibia. - Afr J Ecol 43: 220-224.

Tucker, V. A. 1975. The energetic cost of moving about: Walking and running are extremely inefficient forms of locomotion. much greater efficiency is achieved by birds, fish and bicyclists. - Am Sci 63: 413-419. 
Uriona, T. and Farmer, C. 2008. Recruitment of the diaphragmaticus, ischiopubis and other respiratory muscles to control pitch and roll in the american alligator (Alligator mississippiensis).

- J Exp Biol 211: 1141-1147.

Van Valkenburgh, B. 1987. Skeletal indicators of locomotor behavior in living and extinct carnivores. - J Vertebr Paleontol 7: 162-182.

Van Valkenburgh, B. et al. 2003. Chapter 7: Pack hunting in miocene borophagine dogs: Evidence from craniodental morphology and body size. - Bulletin of the American Museum of Natural History: 147-162.

Voigt, C. C. et al. 2012. Terrestrial locomotion imposes high metabolic requirements on bats. -J Exp Biol 215: 4340-4344.

Watanabe, Y. Y. et al. 2012. The slowest fish: swim speed and tail-beat frequency of Greenland sharks. - J Exp Mar Biol Ecol 426: 5-11.

Weimerskirch, H. 1992. Reproductive effort in long-lived birds: age-specific patterns of condition, reproduction and survival in the wandering albatross. Oikos : 464-473.

Weishampel, D. B. et al. 2004. The Dinosauria. - University of California Press. USA

Weithofer, A. 1887. Zur kenntniss der fossilen cheiropteren der französischen phosphorite. - Mathematisch-naturwissenschaftlich 96: 341-360.

Wellnhofer, P. 1991. The illustrated encyclopedia of pterosaurs. - Crescent Books.

Whitehead, H. and Reeves, R. 2005. Killer whales and whaling: the scavenging hypothesis. - Biol Letters 1: 415-418.

Williams, T. M. 1999. The evolution of cost efficient swimming in marine mammals: limits to energetic optimization. - Philos T Roy Soc B 354: 193-201.

Wilson, E. E. and Wolkovich, E. M. 2011. Scavenging: how carnivores and carrion structure communities. - Trends in Ecology \& Evolution 26: 129-135.

Witmer, L. M. and Ridgely, R. C. 2009. New insights into the brain, braincase, and ear region of tyrannosaurs (dinosauria, theropoda), with implications for sensory organization and behavior. -Anat Rec 292: 1266-1296.

Witton, M. P. 2013. Pterosaurs: natural history, evolution, anatomy. - Princeton University Press, USA. 
Witton, M. P. and Habib, M. B. 2010. On the size and flight diversity of giant pterosaurs, the use of birds as pterosaur analogues and comments on pterosaur flightlessness. - Plos ONE 5: e13982.

Witton, M. P. and Naish, D. 2008. A reappraisal of azhdarchid pterosaur functional morphology and paleoecology. - Plos ONE 3: e2271.

Zelenitsky, D. K. et al. 2011. Evolution of olfaction in non-avian theropod dinosaurs and birds. In: Proc. R. Soc. B 278: 3625-3634. 


\section{Figure Legend}

Figure 1: Factors influencing the proportion of scavenging in a vertebrates' diet. Each of the traits/ factors ranges from low on the left to high on the right. A high value for a given trait can either increase scavenging propensity $(++)$ or reduce it (- -), the same is true for a low value of said trait. Silhouettes ids: Basal Metabolism - Crocodile and Puma, Locomotion cost - Albatross and five-lined skink, Detection rate - shaggy frogfish and Gyps vulture, Carrion availability - fish skeleton and dinosaur skeleton, Food processing - insectivorous bat and Hyena, Competition - Gyps vulture and Dilophosaurus, Facilitation - Gyps vulture and wolverine. All images from phylopic.org, http://creativecommons.org/licenses/by-nc-sa/3.0/ 